\title{
Building Bridges: Linking universities with the manufacturing industry
}

Robert Knutsen, Charlene Steyn and Martin Nicol

ver a decade ago, the South African government, through
what is now the Department of Science and Technology, published a white paper that brought into being a national system of innovation (Department of Arts, Culture, Science \& Technology 1996). This paper set the scene for translating the historical dependence on a resource-based economy into an innovative- and knowledgebased culture by harnessing the intellectual capital of its people. Its motivation was to drive South Africa to become a much more active player in the global manufacturing economy and thus create employment and wealth, particularly amongst the large, previously disadvantaged population. The Provincial Government of the Western Cape, in particular, has determined that much of this manufacturing thrust will be developed from small- and medium-sized enterprises (SMEs). However, growth in the manufacturing sector not only requires a will to do so, but requires support to develop the manufacturing entities into globally competitive industries that will 
create employment and wealth. This means tapping into the worldclass research and development resources that exist at the regional level. Currently, the proverbial chicken-and-egg situation exists: the capability of research institutions remains unlocked and industry is not able to advance.

This article examines how research institutions and industry can be brought together in ways that will both enable industry to grow and will also enrich university research and teaching. Some of the reasons for the lack of progress in this area are discussed, and particular attention is paid to the Cape Initiative in Materials and Manufacturing (CIMM), a not-for-profit company that was formed in 2004 to build bridges between the worlds of the factory and the academy (UCT 2007, p. 55). The article examines a number of innovative approaches undertaken by CIMM and discusses the benefits, challenges and mixed results achieved by the organization to date, and the possible reasons for this. It also examines research done in comparable regions and makes suggestions for ways forward in the Western Cape context.

\section{UNLOCKING THE CAPABILITY OF THE CAPE RESEARCH INSTITUTIONS}

The Western Cape has a great deal of expertise in materials and manufacturing in its universities and research institutions. There is, at the same time, a pressing need on the part of industry to source the most suitable and cost-effective designs, materials and manufacturing methods for their products so they can hold their own against international competitors. Big companies have their own internal research and development (R\&D) laboratories - or they buyout capacity in university departments. Godfrey (2006) makes clear that the power (size and strength) of industry partners has a strong influence on the way in which the interaction between industry and universities have come to be structured and function. But small manufacturers, the SMEs that South Africa is relying on to create more jobs, typically do not have access to the new knowledge in materials and manufacturing that could be critical to their progress. Their operating budgets, profit margins and skills base often inhibits them from entering into negotiations with potential university partners. The Western Cape university environment, indeed that of South Africa as a whole, requires substantial financial support 
for research in addition to that provided by the internal university budgets. For example, funds are required for student bursary support, salary contributions to research support staff and to cover running costs, as well as contributions to the university overhead costs or so-called research levy. These costs associated with accessing $R \& D$ capabilities are significant and are firm barriers for the majority of the small manufacturing industries in the Western Cape.

CIMM was formed in 2004 in response to the above situation. It is the brainchild of a group of academics from the local Western Cape universities who shared a common vision to increase the level of involvement by research entities with smaller manufacturing industries. CIMM is guided by a board of directors that has from its inception been led by the University of Cape Town (UCT) and includes representatives from all the local universities, a national research facility, and industry. The company is sponsored by the Provincial Government of the Western Cape and the business is managed by a full-time CEO (http:/ / www.cimm.co.za/ about.php).

The imperative for a closer link between business and the universities is not one-sided. CIMM was formed by academics who were concerned by the reduction in the number of materials scientists at Western Cape universities. At the end of the 1990's, people saw that there was a threat to the continued existence of a local node of expertise in the area. In order to turn this around, it became necessary to demonstrate the importance of materials science in manufacturing by closer engagement with the manufacturing sector. It was anticipated that, as industry reacted to the services and resources offered by CIMM, manufacturers would become drivers to direct the sort of people that were needed by industry and the sort of research that should be conducted to support business success.

In 2006, CIMM commissioned a detailed assessment of the capability and capacity of the Cape universities and research institutions with respect to materials and manufacturing (Drummond 2007). Funded by the Provincial Government of the Western Cape, the R\&D survey covered 20 departments or centres at the University of Cape Town, the University of the Western Cape (UWC), Stellenbosch University (SU), Cape Peninsula University of Technology (CPUT) and the iThemba Laboratory for Accelerator-Based Sciences, which 
is a national research facility. Tertiary institutions were exposed to CIMM and its activities through the survey, and it encouraged departments, research centres and groups to think about what they can offer to industry in the fields of product design, materials selection, manufacturing selection and advanced materials research. This assessment was also envisaged as a powerful marketing tool for promoting the intellectual property of the Western Cape.

The survey looked at regional capability - available equipment was listed, as were laboratories and published research papers. Excellent resources and strong capabilities were evident, but the survey revealed a particular weakness in human resources. It remained unclear whether or not this capability was allied with a capacity to get involved in work that will assist local industry. There is little doubt that the capability of the Western Cape research institutions is world-class, but there exists problems in unlocking this capability to best serve the needs of a developing manufacturing industry. On the one hand, work done by research departments that is of real value to business but which does not rank as world-class does not get priority from university funding mechanisms. This service role, as relevant as it is for teaching and research, is not the core function of universities. And there are academics that resent the fact that time on expensive and scarce scientific testing equipment is being taken up by marginal work for industry. On the other hand, manufacturers also have a particular view of universities. They see them as being up in the clouds and ignorant about working in the real world. Those who have worked with university people in the past have found that they take ages to do anything. If manufacturers approach a university, it is because they have a problem that needs to be solved. They are looking for a service, not a complex process. Bridges have to be built.

In 2006, a team of researchers led by UCT's Professor Dave Kaplan produced a report on micro-economic development strategy on behalf of the Provincial Government (Kaplan et al. 2006). One of the report's key findings was that if the Western Cape manufacturing industry is to survive and grow, it has to become more involved with R\&D. It is also apparent from CIMM's experience that industry is not adequately defining the areas where they need assistance with research and development. Requiring solutions to emergency 
problems is all very well, but manufacturers are not approaching the universities and research institutions to assist them with mediumterm development work. This South African experience echoes the principal finding of the 2003 Lambert Review of Business-University Collaboration in the UK (Lambert 2003). The report's main conclusion was that 'the biggest single challenge lies in boosting the demand for research from business, rather than in increasing the supply of ideas and services from universities'. This cannot be the responsibility of the universities. Universities are responsible for teaching and research - and for responding to the demands of society in an appropriate manner. It is not their role to organise business. However, universities can turn this to their advantage if they are able to entice industry to assist them with delivery in the teaching programme. CIMM has explored this opportunity and in 2007 developed what is known as the Industry-student project programme (ISPP).

INDUSTRY-STUDENT PROJECT PROGRAMME

The undergraduate engineering programmes at the Western Cape universities all require final year students to complete research projects that are generally conducted over $4-8$ months. In a similar way, the honours (fourth) year of science programmes also requires students to undertake research projects in their specific discipline. A rough estimate indicates that there are at least 800 students who complete these projects each year at Western Cape universities. Designing this number of projects each year is quite onerous and although some academics extend their larger postgraduate research programmes to include undergraduate projects, for many it is difficult to maintain new ideas. This is where industry can assist by providing project ideas that are highly relevant to current manufacturing. Not only will students be exposed to real world problems, which is often lacking in some academic areas, but industry will benefit extensively by obtaining access to research infrastructure at very low cost. There is no cost attached to the student's time, although in some cases it may be helpful to obtain a contribution towards study costs, and access to equipment at universities is generally pre-allocated, since these projects form part of the core teaching business of the various departments. CIMM launched this idea by promoting ISPP to the same departments and 
centres that were surveyed during the 2006 capability and capacity study. CIMM has also advertised this opportunity to industry and has offered its services as a gateway organization to link project ideas with relevant academics and research activities. In the first instance, companies were encouraged to submit proposals to CIMM, who in turn would assess the projects and make the appropriate connection with the universities.

There are very clear benefits to be derived from successful implementation of ISPP, but at the same time, some barriers have been identified. Benefits include:

- individual companies will obtain access to affordable $R \& D$ that will generate an outcome to a specific project within a timeframe more consistent with their expectations

- academics will receive assistance in formulating ideas for projects and

- the initial short-term project interaction could lead to more extended research interaction at postgraduate level (for example, Masters and PhD level).

The net effect will undoubtedly have the potential to improve the competitiveness of the manufacturing industry through technological advancement, and hence the employment opportunities for graduates will grow with positive knock-on effects to the departments that are developing the graduates. Besides these benefits, however, the following challenges will need to be taken into account: companies are often reluctant to divulge relevant information about projects in fear of breach of confidentiality that may jeopardize their competitive advantage. Consequently, they may impose restrictions on the student thesis that ultimately would not be acceptable by the university and as such may impose a barrier to the initiation of the project. A further barrier includes the difficulties experienced as a result of companies not adequately defining the scope of the project. An idea needs to be translated into a work plan so that it can be assessed by the relevant academic before being accepted for allocation to prospective students. CIMM is able to assist in both these regards. Firstly, there are often ways to conceal sensitive information without detracting from the value of the work performed by the student, and 
as long as these issues are identified early in the negotiation process, the company can be protected without any significant detriment to the university examination process. CIMM can facilitate the adoption of non-disclosure agreements that will further protect the relevant parties. Furthermore, CIMM is also in a position to assist with developing the project ideas to the point where the offering becomes much more attractive to academics who may otherwise be inwardly focused towards their established research activities, or in some cases, reluctant to move away from the well trodden approach of recycling projects. It is strongly believed that tremendous advantage can be gained from promoting concepts such as ISPP, but the interventions offered by an organization such as CIMM are vital to ensuring success.

Notwithstanding the above rationale, successes to date have been few. In many instances industry has responded positively, but they often provided insufficient details to properly define the objectives and anticipated outcomes of the proposed projects. Academics have been slow to take up project ideas. Perhaps this is not too surprising given the fact that the ISPP process is a departure from the conventional approach to final year projects. CIMM, and even more so ISPP, is not yet proven and hence academics are somewhat reluctant to venture into this territory. This does not mean that the idea is not worthwhile or cannot work. Instead it requires much more detailed intervention by CIMM, at least initially, to ensure systematic definition of the project in the first instance, along with full project management support to ensure that all requirements are met in a timely fashion. It needs to be remembered that ISPP does not aim to provide research support for universities in the normal way that one may expect from university-industry collaborations, but rather provides access for small companies to test facilities and expertise at a relatively low cost. The universities in turn obtain assistance with curriculum delivery in regard to final year project offerings. CIMM needs to invest considerable effort to prove that these arrangements can work and that they do offer benefits to all concerned.

\section{THE SPIN-IN CONCEPT}

Whilst the national system of innovation encourages higher education institutions and science councils to include patents, 
business plans and proactive liaisons with industry in their research goals, the evolution of this has been slow. The reasons are complex and varied as already described, but undoubtedly include the strong academic tradition to publish in high impact journals and the fact that academics and researchers, by their very nature, are not entrepreneurial or business oriented. Furthermore, a study commissioned by the National Advisory Council on Innovation (NACI 2007) revealed that both article and book output had stagnated, signalling that the underlying human capital in academia is being stretched to the limit. In other words, academics are engaged disproportionately in teaching and administration, and perhaps are spending too much time meeting reporting deliverables demanded by funding bodies as opposed to translating their research outputs into peer review articles and books. Despite this, however, there are some significant successes where research ideas and inventions have been translated into commercial outputs. A recent noteworthy success has been the formation of Hot Platinum (http:/ / www.hotplatinum. com) that developed from research sponsored by the Innovation Fund through the Department of Science and Technology (http:/ / www. dst.gov.za). The research led to the novel design and manufacture of induction furnaces for the jewelry industry with particular emphasis on high temperature melting of platinum alloys.

In an age where the 'win-win' situation is often targeted, the propulsion of research outputs towards the creation of commercial 'spin-out' companies can benefit all parties who get involved in the activity. The formation of a spin-out company is probably one of the ultimate measures of success of the national innovation system promoted by South Africa's Department of Science and Technology. Since academics can remain attached to the spin-out company, they are able to supplement their regular income, which in itself provides just reward for commitment to teaching and research. Proliferation of such opportunities may even assist in attracting more people into academia and hence relieve somewhat the position described in the aforementioned NACI report. In these same companies, graduates find careers that are tailor-made for their high level training. Furthermore, successful companies will create employment positions for support staff and increased economic activity along the value chain. The University of Stellenbosch in the Western Cape is well 
known for having an institutional culture and infrastructure that encourages and supports entrepreneurship among students as well as staff members A technology transfer company called InnovUS was formed in 1999 to facilitate the commercial exploitation of intellectual property emanating from the University's faculty members and students (http: / / www.innovus.co.za). There are already several examples where breakthroughs and inventions have led to the formation of spin-out companies including Aquanutro (http:// www.aquanutro.com), Sunspace and Information Systems (http:// www.sunspace.co.za) and Diacoustic Medical Devices (http:/ / www. diacoustic.co.za). Of course, success also depends on the provision of adequate venture capital to support the formation of the spin-out company and often this vital ingredient may be the critical barrier to success, particularly in the current global environment where the opportunities to obtain credit are much reduced. In addition, there is always great risk in forming new commercial ventures.

An alternative to the formation of spin-out companies is to develop the corollary which we call the 'spin-in' company. In this case, the source of ideas may originate from an existing company, but still require substantial research and development. Since most manufacturing operations are not able to single-handedly afford the cost of research, they require partners who are able to offer assistance at relatively low cost. Universities and science councils are well positioned and equipped to provide this form of assistance, particularly if the activity can slot into the regular senior undergraduate and postgraduate research programmes. However, there are several reasons why this has not been happening, as already discussed in this article. The problem may be addressed, however, by examining whether or not most of the barriers can be overcome if the researchers are able to obtain a partnership in commercializing the output. So, instead of demanding full cost recovery for executing the research proposed by the external manufacturing company, the costs are significantly reduced and a commercial partnership between the research institution (university or science council) and the manufacturing company is initiated. In this way, the end point is similar to the formation of a spin-out company, except that the initiator is the manufacturing company, which is most likely an $\mathrm{SME}$, and not the research institution. The researcher and institution 
continue to be part of the manufacturing operation long after the initial research is completed and the resultant expansion of the manufacturing activity could conceivably lead to additional job creation. In essence, the concept of spin-in companies epitomizes the intentions of CIMM. The bringing together of industry and academia to support and grow the activities of industry is promoted by creating stronger networks between the two parties. The industrystudent project programme (ISPP) has huge potential to lead to 'spin-in' activity, thereby creating new revenue streams for research institutions, providing additional income for researchers, and growing the manufacturing economy with ultimate job and wealth creation.

A 2006 report for the European Commission on regional advantage considers the case of 'technology-based new firms [that are] a special category of knowledge-based firms' (European Commission 2006, p. 53). Most of these firms are created as spin-offs from existing private industry but 'a substantial part of the new technology-based firms is linked to university activities'. This is despite the fact that 'creating and exploiting new commercial ideas are not part of the traditional core operations' of universities. The report says that 'a small share of the new technology-based firms are created by university researchers themselves, that is, direct university spin-offs' but it also highlights a different process where 'external entrepreneurs' - private firms progress by 'exploiting university research made by others'. Although the phrase 'spin-in' is not used here - and the possibility that the research may owe its direction to the entrepreneur rather than to the academic team is not made explicit - this co-development of 'previously missing technologies' is exactly the process that CIMM is able to encourage.

\section{Promoting interaction between ACADEmics AND Industry}

As already indicated, the fact that industry is often not able to adequately access assistance from higher education institutions (HEIs) is partly due to the limited capacity on the part of academics and researchers. University and research agendas are such that they place huge demands on personnel and consequently projects are either taken on with subsequent poor delivery, or they do not get out of the starting blocks at all. So, despite the efforts of CIMM and the good intentions of the academics who become involved, the 
capabilities remain unlocked. That is, it is not enough to provide bridging services as offered by CIMM, what is also needed is a third party that can take over the management of the project and thus enable the academic partner to concentrate on providing expert input to plan and conduct appropriate research and investigation without having to be too concerned with logistics. Not only does this lessen the load and lower the barrier to entry for academic involvement, but it also allows the academic party to feel more at ease in the sense that they are not deviating too much from their regular work practice. Most academics are not inclined to business and therefore may feel uncomfortable if expected to drive and manage the entire project, particularly where it may involve logistics that are far removed from the regular research environment. A recent project example involving the UCT Centre for Materials Engineering is discussed below.

A large consortium involved in the construction and management of a rock retainer system on the slopes of Table Mountain in Cape Town approached the Centre for Materials Engineering for assistance in providing solutions to ongoing corrosion problems experienced by their wire rope barriers. From the outset it was clear that the problems were complex and required in situ examination, laboratory simulation and in situ trials over an extended period. Large wire rope barrier systems are certainly not the typical samples that a materials research laboratory handles and furthermore, alternative coating systems for the wire ropes were required to be proposed and evaluated. The latter expertise in coating systems was not available at UCT and consequently a third party consultant, who was accessed through the CIMM network and was able to independently conduct research related to relevant coating practices, was invited to join the project. In addition, an important requirement for the third party involvement was to manage and execute the process of sample extraction from the mountain slopes, set up simulation tests at another third party laboratory that was able to provide test facilities not available at UCT, and arrange the placement of wire rope control samples at strategic locations on the mountain slopes.

The expertise provided by UCT was thus able to concentrate on the assessment of corrosion damage and the interpretation of mechanisms that were responsible for the premature degradation of the original installations on the mountain slopes. Consequently, the 
academic involvement was limited to direct scientific investigation, interpretation and report compilation. The impact on the regular activities of the Centre for Materials Engineering was very limited whilst the value of the output for all parties was substantial. The knowledge developed at UCT assisted the third party consultant in devising a successful coating system that was able to provide a solution to the severe corrosion problems experienced by the wire ropes. Although the outcome of this project was highly successful, it was acknowledged by the academic partner that it was unlikely that the project would have advanced towards any reasonable conclusion without the assistance of the third party consultant. CIMM believes that this mode of involvement should be encouraged and promoted more widely to academics and researchers. Essentially this approach provides a very attractive path for academic-industry interaction without drawing too heavily on the university and research institution resources. Furthermore, the sound business approach inherent in successful consultancies ensures that the client is adequately serviced, which greatly diminishes the entrenched poor reputation for services provided by academia. The opportunities that extended academic expertise can add to the business activities of regular consultants should also not be ignored. CIMM thus aims to identify consultants who are able to participate in the networks that exist within the local manufacturing sectors.

The important role that universities can play in regional innovation systems is widely acknowledged (European Commission, 2006; TRRA 2007). This refers traditionally to processes of technology transfer, creation of knowledge-intensive spin-off companies, and the establishment of science parks and incubators (European Commission 2006, citing Jones-Evans et al. 2001). Both CIMM's development of the 'spin-in' concept and its identification of the useful 'intermediary' role that can be played by consultants are particularly suited to the context of the Western Cape where the immediate need is to improve the performance and competitiveness of existing manufacturing firms. As the links between business and academia increase in number, the availability of more modes of interaction will promote deeper levels of collaboration. The comments of the European Commission report are equally applicable: 'Access to knowledge produced through research at regional universities serves as a 
locational advantage for firms in the region, especially in the context of SMEs. When constructing regional advantage, regional innovation performance may thus be strengthened by regional firms tapping into the knowledge reservoir of the local universities against relatively few costs'. As CIMM's experiences show, there are various ways of doing this. The networks and social capital created around these innovative approaches may, in turn, improve the environment for science parks, incubators and the other 'traditional' development advantages associated with universities in developed countries.

\section{LEARNING FROM OTHERS}

In its 2007 discussion document on 'The role of universities in economic development', the Toronto Regional Research Alliance (TRRA), points to the 'significant body of literature that documents the importance of university activities to the innovation process generally and to technology-based industrial performance'. One of its main points, however, is that 'the precise nature of the university's role in the knowledge-based economy - and its ability to perform the roles ascribed to it - is still being explored' (TRRA 2007). In the Western Cape, CIMM's activities can be seen as part of this quest. There are at least two elements that shape CIMM's particular experience in this regard - firstly: the need to operate at a scale and in a style that matches the much weaker technology and innovation environment compared to that of more developed centres in other parts of the world. The TRRA report highlights the need for universities to tailor their efforts to fit 'the characteristics of their own regional innovation ecosystem'. Miles (2007), in a striking analogy, characterises the relatively large (in the UK) and successful Cambridge high-technology cluster as 'small mammals' compared to the 'big gorilla' companies of Silicon Valley in the USA. South Africa does not even rate on such a scale. Secondly: the need for the project to foster a common approach across a number of research and learning institutions in order to provide a sufficiently broad base of service and expertise in materials issues (collaboration between universities is critical to its success).

About ten years ago, KnowledgeNorthWest (KNW) was created as a collaborative project between the higher education institutions in England's North West and was established to support knowledge 
transfer and innovation in the region by facilitating business access to the vast and wide ranging knowledge and expertise available across the region's HEIs. The project operated for six years until early 2006 with almost $£ 2.3 \mathrm{~m}$ funding drawn down during the life of the project (North West Universities Association 2007). In many respects, the objectives of CIMM mimic that of KNW in that the project had two key arms including the promotion of a knowledge and skills brokerage service and the facilitation of higher education strategic engagement with regional priority clusters and sectors. The knowledge and skills brokerage service provided a single point of contact to facilitate business access to the knowledge, expertise and skills available within the region's knowledge base. In the review of the KNW model (North West Universities Association 2007), it is clearly evident that the single point of access to the region's HEIs and the simultaneous broadcasting of enquiries across the knowledge base proved to be valuable to business. However, it was firmly recognized that the full potential was compromised by the low-level intervention at the HEI-business interface. The brokerage role was undertaken by relatively junior, generalist staff and the offer was available to organizations of all types and sizes, across all sectors. Consequently, this generalist approach increased the intervention required by HEIs both at central level, to understand and articulate the nature of the enquiry prior to processing, and at the academic level, in terms of the exploratory dialogue required with the client.

This experience demonstrated the considerable support that some companies, and in particular SMEs, need to effectively access and utilize the knowledge base, both in the early stages when diagnosing and articulating their needs, and later to maintain communications, and develop and deliver the idea. CIMM is different in this regard in that the focus of attention is aimed at providing materials and manufacturing support only and consequently the target industry market is much more concentrated. In this way the tailored expertise of the CEO and the board members enables a much more efficient interface between HEIs and industry than that experienced by KNW. In addition, it is now recognized that the project management role that is offered by third party consultants can be vital in ensuring that projects are completed to the satisfaction of both parties. 
Another important aspect highlighted in the KNW review report refers to the manner in which measurable outputs are evidenced to substantiate the level of funding awarded to sustain the operation of KNW. Outputs such as job creation and sales targets were identified but it has since been recognized that these hard economic outputs may be inappropriate to measure the impact on business and industry (North West Universities Association 2007). In many cases companies were either too busy or were too difficult to contact or engage with to enable effective follow-up that sufficiently reflected the outcome of the intervention. Furthermore, given the time lines of some developments, additional outputs may yet be delivered but will fall outside of the project and follow-up period. This remains a challenge as it is reasonable to expect that funding agencies will require some form of evidencing of outputs and CIMM will need to rise to this challenge in order to secure sustainable funding from Government, industry and other agencies.

\section{Conclusion}

There is little doubt that universities and research institutions have much more to offer than core teaching and high level research. It is also quite obvious in many situations that industry, and in particular the manufacturing industries, require assistance to advance their capabilities and products to remain competitive in the global economy. Bringing these two entities together can only increase the strength of both the teaching/research environment and the manufacturing industry. Since this marriage does not happen easily in many situations, the role of an intermediary is critical.

In the Western Cape region, the willingness of universities and industry to form networks has been demonstrated through the formation of the Cape Initiative in Materials and Manufacturing. While this 'bridging' organization is still in its early stages, it offers much potential as a means to enhance and grow the activities of the universities and industry and hence deliver direct benefits to graduates and the local economy.

\section{REFERENCES}

Department of Arts, Culture, Science and Technology 1996, 'White paper on science and technology', Republic of South Africa, Pretoria, viewed 9 June 2009, http:/ / www.dst.gov. $\mathrm{za} /$ publications-policies/legislation/white papers/ 
Drummond, M 2007, 'R\&D capability assessment in materials and manufacturing', unpublished report for Cape Initiative in Materials and Manufacturing, Cape Town.

European Commission 2006, 'Constructing regional advantage: Principles - perspectives - policies report', European Commission, Brussels, viewed 19 June 2009, http:/ / www. dime-eu.org/files/active/0/regional advantage FINAL.pdf

Godfrey, S 2006, 'Partnerships and networks in new materials development', in G Kruss (ed.), Creating knowledge networks: Working partnerships in higher education, industry and innovation, HSRC Press, Cape Town, pp. 94-126.

Jones-Evans, D, Cooke, P, Klofsten, M \& Paasio, A 2001, 'Entrepreneurial universities from the periphery', European Commission Publication EUR 19846 - The regional level of implementation of policies, Brussels.

Kaplan, D, Daniels, R, Lorentzen, J \& Morris, M (eds) 2006, 'Micro-economic development strategy for the Western Cape - Synthesis report: 2006', Department of Economic Development and Tourism, Provincial Government of the Western cape, Western Cape.

Lambert 2003, 'Lambert Review of Business-University Collaboration: Final report December 2003', HM Treasury, London, viewed 3 June 2009, http:/ / www.hm-treasury. gov.uk/

Miles, N 2007, 'The state of the innovation economy in the UK 2007', Oxford to Cambridge Arc, Norwich Research Park, pp. 74.

National Advisory Council on Innovation South Africa 2007, 'Human capital and the South African knowledge base: Annual report 2006-2007', National Advisory Council on Innovation, Pretoria, viewed 9 June 2009, http: / / www.naci.org.za/pdfs / NACIreports /

North West Universities Association, 2007, 'KnowledgeNorthWest final report September 2007', North West Universities Association, Manchester, UK, viewed 2 July 2009, http:/ / www.nwua.ac.uk/docs/pdf/KNW Final Report FINAL 200907.pdf

Toronto Regional Research Alliance 2007, 'The role of universities in economic development: Discussion document prepared for TRRA research working group', TRAA, Ontario, Canada, June 2007, pp. 63, viewed 7 June 2009, http: / / www.trra.ca / en/ reports / TRRAReports.asp

University of Cape Town 2007, 'Social responsiveness report 2007', University of Cape Town, Cape Town, pp. 55-59. 